\title{
Application of Internet and Artificial Intelligence in Humanized Nursing Teaching
}

\author{
Wang Xiaolong ${ }^{1^{*}}$ \\ ${ }^{1}$ Zhengzhou University of Industrial Technology, Zhengzhou, Henan, 451150, China \\ *Corresponding Author.
}

\begin{abstract}
:
In nursing teaching, students are required to apply the learned theoretical knowledge to practical operation, and have the ability to comprehensively analyze and solve problems. At present, the traditional teaching mode is mostly used in nursing teaching in China. "Indoctrination" with textbooks as the theoretical basis and teachers' teaching as the main teaching method " With the rise of network technology and the application of modern educational technology in teaching, the research direction and focus of PBL have gradually shifted to the integration of network environment and PBL teaching mode This paper studies the application of Internet and artificial intelligence in humanized nursing teaching. This paper focuses on PBL teaching method based on network environment (WPBL) The results show that PBL teaching mode under the network environment does have many advantages in medical nursing education. This method can effectively cultivate nursing students' problem-solving ability and critical thinking ability, which is consistent with the goal of nursing education.
\end{abstract}

Keywords: Nursing teaching, network technology, artificial intelligence, PBL teaching method.

\section{INTRODUCTION}

Geriatric nursing is a subject that takes the elderly and the elderly society as the research object, understands the laws of physiological, pathological and psychological changes of the elderly and the relationship between society and the elderly, so as to study, diagnose and deal with the response of the elderly to their existing and potential health problems [1-2]. In 1969, Howard barrows, an American professor of Neurology, initiated the PBL model in Canada and applied it to teaching [3]. Because of its ideal effect, it was quickly popularized in the field of medical education all over the world [4]. PBL has also been widely used in the field of nursing education [5-6]. 
Article History: Received: 28 October 2021 Revised: 05 December 2021 Accepted: 10 January 2022 Publication: 28 February 2022

Although PBL teaching mode has not been applied in nursing teaching for a long time in China, it has been studied among nursing students at all levels, and has accumulated some experience from technical secondary school, higher vocational college to undergraduate and graduate students [7]. The pioneers also put forward the problems existing in the application process and the countermeasures to solve them. With the rapid development of network technology and modern education technology, the application of PBL teaching mode and its combination in nursing education will be an important topic. The research on PBL teaching mode under the network environment has just started. How to use the advantages of the network to design and implement learning content, learning activities and learning evaluation needs further in-depth research [8]. The application effect of PBL teaching under the network environment also needs further verification.

\section{MATERIALS AND METHODS}

Based on the study of PBL learning activities, combined with the characteristics of the network environment, from the diachronic dimension, the process elements of WPBL teaching mode include five links: presenting problem situations, analyzing problems, solving problems, summarizing and reflecting, analyzing and evaluating. The basic process of WPBL learning activities is: teachers set problem situations according to teaching content and learning objectives. After analyzing the problem situation, students determine some of the problems they want to study. Put forward the plan arrangement of problem solving through autonomous learning and obtaining information resources of problem solving under the network environment. Group division of labor and cooperation to further obtain relevant problemsolving resources, through discussion, reflection and summary, to construct a solution to the problem; Analyze and evaluate the solution to the problem.

This study is a kind of experimental study. Participants: convenience sampling selected 2018 nursing college sophomores who took the course of geriatric nursing in the a nursing college of Zhengzhou from March to May 2020 as the research object. All students expressed their willingness to participate in the study. A total of 56 women, aged 18-21, were tested for critical thinking ability before intervention. The design of problems is the key in WPBL teaching. The characteristics of geriatric nursing should be considered, such as strong practicality and large span of disciplines.

Problems must be based on teaching materials and learning objectives. At the same time, we should consider the close combination of theory and practice, and conform to students' cognitive situation. Students can understand and have a strong interest in learning. Students can master knowledge and complete learning objectives through problem solving. In the elderly nursing teaching, according to the learning objectives, integrate with other relevant curriculum contents, and design the problem situation under the network environment.

In this study, the first type of PBL teaching mode under the network environment is applied, 
Article History: Received: 28 October 2021 Revised: 05 December 2021 Accepted: 10 January 2022 Publication: 28 February 2022

that is, the network is only used as an open communication platform. Students obtain and exchange information through the network. The network is the way for students to obtain relevant learning materials to solve problems. Group members can communicate and discuss through the network and conduct online consultation. Teachers can also communicate with students through the network to give guidance, provide reference suggestions and evaluation in time.

An important index of PBL teaching effect is critical thinking ability. The Chinese version of the critical thinking ability measurement table translated and revised by Peng MEICI and others was selected to score the critical thinking ability of the two groups of students. After the course, the students in the experimental group and the control group were examined in a closed book way, with a total score of 100 . The questions in the test paper were noun explanation questions, blank filling questions, multiple-choice questions, question and answer questions and discussion questions. The test contents and time were the same, and there was no guidance in any form before the test. On the basis of theoretical study, the students in the control group and the experimental group completed a health education material for the content of common diseases of the elderly, and made it into teaching aids to educate the elderly in the elderly nursing practice course. According to the completeness, correctness, pertinence, observability and novelty of the teaching aids, the teachers divide the results into three grades: excellent, medium and poor. The scoring teachers do not know the grouping of students. A self-made questionnaire was used to investigate 28 students in the experimental group, and a descriptive qualitative analysis was made on the teaching effect of WPBL. The questionnaire had 9 closed questions and 1 open question.

This study is a kind of experimental study. 56 students with convenient sampling are randomly assigned to the experimental group and the control group. The experimental group adopts WPBL mode teaching, while the control group adopts traditional teaching mode teaching. The data are statistically analyzed by Excel 2003 and SPSS13.0.

\section{RESULT}

There was significant difference between the two groups in the score of geriatric nursing theoretical knowledge test. By Mann Whitney $\mathrm{U}$ rank sum test, $\mathrm{z}=2.247, \mathrm{P}=0.025$. The theoretical test scores of the experimental group were higher than those of the control group. See Table 1.

\section{TABLE I. Comparison of theoretical results}

\begin{tabular}{|c|c|c|c|c|}
\hline PROJECT & M & Q & Z & P \\
\hline Experimental group $(\mathrm{n}=28)$ & 85.500 & $90.000-66.250$ & 2.247 & 0.025 \\
\hline
\end{tabular}


Article History: Received: 28 October 2021 Revised: 05 December 2021 Accepted: 10 January 2022 Publication: 28 February 2022

\begin{tabular}{l|l|l|l|l|} 
Control group $(\mathrm{n}=28)$ & 80.000 & $82.750-69.250$ & & \\
\hline
\end{tabular}

The grade evaluation of the self-made health education teaching aids of the two groups was statistically significant with Mann Whitney $\mathrm{U}$ rank sum test, $\mathrm{z}=2.818, \mathrm{P}=0.005$. The results of self-made teaching aids in the experimental group were better than those in the control group, with significant difference. The results of self-made teaching aids in the experimental group were less than those in the control group, with significant difference. See Table 2.

TABLE II. Comparison of results of self-made teaching aids

\begin{tabular}{|c|c|c|}
\hline PROJECT & EXPERIMENTAL GROUP $(\mathbf{N}=\mathbf{2 8})$ & CONTROL GROUP $(\mathbf{N}=\mathbf{2 8})$ \\
\hline EXCELLENT & $7(25 \%)$ & $1(3.6 \%)$ \\
\hline MIDDLE & $20(71.4 \%)$ & $21(75.0 \%)$ \\
\hline BE POOR & $1(3.6 \%)$ & $6(21.4 \%)$ \\
\hline M & 33.27 & 23.73 \\
\hline
\end{tabular}

After the intervention, the total score of students' critical thinking test in the experimental group (WPBL teaching method) was improved, with a significant difference $(\mathrm{t}=-3.087, \mathrm{P}=$ 0.005), that is, WPBL teaching method has an effect on improving students' critical thinking ability. See Table 3 .

TABLE III. Comparison of critical thinking ability of students in the experimental group before and after intervention $(n=28)$

\begin{tabular}{|c|c|c|c|c|c|}
\hline DIMENSION & FRONT $(\mathbf{X} \pm \mathbf{S})$ & $\mathbf{R E A R}(\mathbf{X} \pm \mathbf{S})$ & $\mathbf{D} \pm \mathbf{S}$ & $\mathbf{T}$ & $\mathbf{P}$ \\
\hline Looking for the truth & $36.68 \pm 6.49$ & $43.18 \pm 5.28$ & $-6.50 \pm 7.22$ & -4.761 & 0.000 \\
\hline Open mind & $42.57 \pm 5.52$ & $43.93 \pm 5.58$ & $-1.36 \pm 7.70$ & -0.932 & 0.36 \\
\hline Analytical ability & $46.50 \pm 4.26$ & $47.00 \pm 6.70$ & $-0.50 \pm 8.37$ & -0.316 & 0.754 \\
\hline Systematic ability & $39.82 \pm 6.22$ & $43.57 \pm 6.25$ & $-3.75 \pm 8.82$ & -2.250 & 0.033 \\
\hline $\begin{array}{c}\text { Self confidence in } \\
\text { critical thinking }\end{array}$ & $40.64 \pm 5.78$ & $46.64 \pm 6.92$ & $-6.00 \pm 8.04$ & -3.950 & 0.001 \\
\hline $\begin{array}{c}\text { Thirst for knowledge } \\
\text { Cognitive maturity }\end{array}$ & $44.89 \pm 5.72$ & $48.46 \pm 7.91$ & $-3.57 \pm 7.55$ & -2.053 & 0.049 \\
\hline Total score & $293.86 \pm 28.57$ & $317.21 \pm 32.22$ & $-23.36 \pm 40.03$ & -3.087 & 0.005 \\
\hline
\end{tabular}


Article History: Received: 28 October 2021 Revised: 05 December 2021 Accepted: 10 January 2022 Publication: 28 February 2022

Qualitative evaluation of the effect of Web-based PBL teaching model in geriatric nursing teaching. The results show that most students hold a positive attitude towards the learning effect of geriatric nursing under this new model. For example, $85.7 \%$ of students think that WPBL is better than the traditional teaching method, $89.3 \%$ of students are interested in the WPBL teaching method of this course, and $96.4 \%$ of students hope to continue to use this teaching model. Most students believe that WPBL teaching method has improved their abilities in all aspects. For example, $89.3 \%$ of the students believe that WPBL teaching method makes it easier for them to understand and master the knowledge they have learned, and $92.9 \%$ of the students believe that WPBL teaching method can improve their autonomous learning ability and information processing ability. $85.7 \%$ of the students thought that WPBL teaching could improve the ability of good communication with students and the spirit of cooperation. While the students affirmed $100.0 \%$ of the teachers' leading role in WPBL, $32.1 \%$ of the students thought that the teaching mode needed a lot of time and was not worth it. See Table 4.

\section{TABLE IV. Effect evaluation of students' implementation of WPBL teaching mode in geriatric nursing $(n=28)$}

\begin{tabular}{|c|c|c|}
\hline PROJECT & YES (\%) & NO (\%) \\
\hline $\begin{array}{l}\text { Do you think WPBL is better than traditional teaching } \\
\text { method? }\end{array}$ & $24(85.7 \%)$ & $4(14.3 \%)$ \\
\hline $\begin{array}{l}\text { Are you interested in the WPBL teaching method of this } \\
\text { course? }\end{array}$ & $25(89.3 \%)$ & $3(10.7 \%)$ \\
\hline $\begin{array}{l}\text { This teaching mode takes up a lot of time. Do you think it's } \\
\text { worth it? }\end{array}$ & $19(67.9 \%)$ & $9(32.1 \%)$ \\
\hline $\begin{array}{l}\text { Does WPBL teaching method make it easy for you to } \\
\text { understand and master the knowledge you have learned? }\end{array}$ & $25(89.3 \%)$ & $3(10.7 \%)$ \\
\hline Do you want to continue to use this teaching mode? & $27(96.4 \%)$ & $1(3.6 \%)$ \\
\hline $\begin{array}{c}\text { Can WPBL teaching method improve your autonomous } \\
\text { learning ability? }\end{array}$ & $26(92.9 \%)$ & $2(7.1 \%)$ \\
\hline $\begin{array}{l}\text { Can WPBL teaching method improve your information } \\
\text { processing ability? }\end{array}$ & $26(92.9 \%)$ & $2(7.1 \%)$ \\
\hline $\begin{array}{l}\text { Can you communicate well with your classmates and } \\
\text { cooperate to complete the task in WPBL teaching? }\end{array}$ & $24(85.7 \%)$ & $4(14.3 \%)$ \\
\hline Do teachers play a leading role in WPBL? & $28(100.0 \%)$ & $0(0.0 \%)$ \\
\hline
\end{tabular}

\section{IV.DISCUSS}


The application of WPBL in medical education in China has been proved many times to improve students' theoretical achievement and practical ability. The same results were also obtained in this application to elderly nursing teaching:

(1) WPBL improves students' theoretical performance. The application of WPBL teaching mode in geriatric nursing teaching improved the students' theoretical scores: the scores of geriatric nursing theoretical knowledge of the two groups were compared. There was a significant difference between the two groups by Mann Whitney $\mathrm{U}$ rank sum test $(\mathrm{Z}=2.247, \mathrm{P}$ $=0.025)$. The theoretical test scores of the experimental group were higher than those of the control group.

(2) WPBL improves students' practical ability. The application of WPBL teaching mode in geriatric nursing teaching has improved students' practical ability: the self-made health education teaching aids of the two groups were compared, and the scores of the two groups were compared. Mann Whitney $\mathrm{U}$ rank sum test $(\mathrm{Z}=2.818, \mathrm{P}=0.005)$, with significant difference and statistical significance. The results of self-made teaching aids in the experimental group were better than those in the control group, with significant difference.

The application of WPBL in elderly nursing theory and practice teaching was successful. In this study, $85.7 \%$ of the students thought that WPBL teaching method was better, and $89.3 \%$ of the students thought that WPBL was helpful for understanding and mastering knowledge. WPBL realizes the extension of learning, increases the content of learning, and students master the initiative in the learning process, so that students' comprehensive ability to solve and analyze problems is improved, so as to improve the learning effect and students' theoretical and practical ability

The improvement of comprehensive ability is mainly reflected in the following three aspects:

(1) WPBL improves students' autonomous learning ability. In WPBL teaching mode, teachers no longer instill knowledge into students. The acquisition of knowledge mainly depends on students' own analysis of problems and the use of network resources. This requires students to learn independently, actively construct knowledge system, constantly reflect and critically think about problems, otherwise the learning effect is not as good as the traditional teaching method, because no one will directly instill the ready-made knowledge results. In this study, $92.9 \%$ of students self-rated WPBL teaching model is conducive to the improvement of autonomous learning ability. In the process of elderly nursing teaching, teachers provide students with real problem situations and rich network resources to make students interested in the learning of the course and promote their autonomous learning.

(2) WPBL helps to cultivate students' communication ability and collaborative spirit. In the WPBL teaching process of elderly nursing, group learning is a main form. After the problem situation is displayed, the team leader organizes the team members to complete the whole learning process. We should go through the learning process of establishing problems, assigning 
Article History: Received: 28 October 2021 Revised: 05 December 2021 Accepted: 10 January 2022 Publication: 28 February 2022

tasks, obtaining resources online, group communication and discussion, group communication and discussion, recording the discussion contents, and finally uploading, evaluating and reflecting the solution to the problem in the form of PPT and electronic materials. In the process of knowledge construction, we should complete the same goal and task together, but the personal roles and assigned work are different. Members must improve their personal participation, maintain communication with other members of the group to promote the group to solve problems, and cultivate students' communication and cooperation ability in the process of analyzing and solving problems. In this study, $85.7 \%$ of the students believe that their communication and cooperation skills have been improved

(3) WPBL teaching improves students' ability of information acquisition and processing. The implementation of WPBL teaching mode in elderly nursing is conducive to the cultivation of students' information literacy. $92.9 \%$ of students believe that their ability to obtain and process information has been improved. Teaching under the network environment requires students to find materials and information related to problem learning content in the rich network resource environment. In elderly nursing teaching, in addition to providing basic learning resources, students also need to use other search tools to find relevant network resources. Students use these network resources to obtain knowledge. In the process of analysis, processing, processing and transmission, they can naturally improve the ability of information acquisition and processing.

\section{CONCLUSION}

Based on the study of PBL and constructivism theory, I this paper puts forward the teaching design of implementing PBL teaching mode based on network environment in elderly nursing teaching, and draws the following conclusions: in elderly nursing teaching, the effect of WPBL teaching method is better than the traditional teaching method. The students' critical thinking ability is improved, and the scores of theoretical scores and practice self-made health education teaching aids are also high. Students hold a positive attitude towards the evaluation of the teaching effect of implementing WPBL in elderly nursing teaching.

\section{REFERENCES}

1. Goda, Y., Morimoto, M. , Irie, K. , Kobayashi, S. , Ueno, M. , \& Moriya, S. (2017) "Switch to miriplatin for multinodular hepatocellular carcinoma unresponsive to transarterial chemoembolization with epirubicin: a prospective study". Japanese Journal of Clinical Oncology, 16. 
Article History: Received: 28 October 2021 Revised: 05 December 2021 Accepted: 10 January 2022 Publication: 28 February 2022

2. Hashemzadeh, H. , \& Raissi, H. (2017) "The functionalization of carbon nanotubes to enhance the efficacy of the anticancer drug paclitaxel: a molecular dynamics simulation study". Journal of Molecular Modeling, 23(8), 222-227.

3. Mochida, Y. , Cabral, H. , \& Kataoka, K. (2017) "Polymeric micelles for targeted tumor therapy of platinum anticancer drugs". Expert Opinion on Drug Delivery, 1-16.

4. Mohiyuddin, S. , Naqvi, S. , \& Packirisamy, G, (2018). "Enhanced antineoplastic/therapeutic efficacy using 5-fluorouracil-loaded calcium phosphate nanoparticles". Beilstein Journal of Nanotechnology, 9, 2499-2515.

5. Nausica Català Tella, Arnaiz, C. S. , Gatius, J. R., Torres, O. Y. , \& Leonardo Galván Santiago. (2017). Assessment of the length of sick leave in patients with ischemic heart disease. BMC Cardiovascular Disorders, 17(1), 32-38.

6. Qingrong, Z. , Yan, S. , Haijiao, X., Lulu, Z., Jing, G. , \& Junguang, J., (2018) "Evaluating the efficacy of the anticancer drug cetuximab by atomic force microscopy". RSC Advances, 8(39), 21793-21797.

7. Wang, R. , Liu, X. , Wang, C. , Ye, X. , Xu, X. , \& Yang, C., (2017) "Higher coronary artery calcification score is associated with adverse prognosis in patients with stable angina pectoris". Journal of Thoracic Disease, 9(3), 582-589.

8. Zhao, Y., (2018) "Cluster analysis for syndromes of real-world coronary heart disease with angina pectoris". Frontiers of Medicine, 12(5), 566-571. 